\title{
Carga de Trabalho e Rotatividade na Função de Frentista
}

\author{
Mário César Ferreira \\ Odaléa Novais Freire
}

\section{RESUMO}

O artigo aborda a inter-relação da carga de trabalho com a rotatividade sistemática em cenário sociotécnico de atendimento ao público de um posto de distribuição de combustível. O enfoque em ergonomia francofônica no estudo da temática articula três dimensões analíticas complementares: serviço de atendimento ao público; a discrepância entre trabalho prescrito - trabalho real, e os componentes físico, cognitivo e psíquico da carga de trabalho. Os resultados fornecem um quadro preliminar para a compreensão da rotatividade de pessoal, contrapondo-se ao argumento institucional da inadaptabilidade dos funcionários, enfatizando o papel multifuncional dos frentistas e a sobrecarga cognitiva exigida para o desempenho da função.

Palavras-chaves: ergonomia; serviço de atendimento ao público; carga de trabalho; rotatividade.

\begin{abstract}
The article approaches the interrelation between work load and systematic turnover in a socialtechnical scenario of a gas station public customer service. The Francophonic focus on the study of this theme articulates three complementary analytical dimensions: public attendance service; discrepancy between prescribed task - real work; and the physical, cognitive and psychic compounds of the work load. The results suggest a preliminary understanding of turnover, which contrasts to the institutional argument of the worker's non adaptability, emphasizes the multifunctional role of the employee and the cognitive overload required to the execution of the function.
\end{abstract}

Key words: ergonomics; public customer service; work load; turnover. 


\section{INTRODUÇÃO}

O objetivo deste artigo é abordar a inter-relação da carga de trabalho dos funcionários com a ocorrência da alta rotatividade de pessoal no contexto sociotécnico de postos de abastecimento de combustível. Trata-se de um estudo de caso em ergonomia, de caráter exploratório, no qual se busca investigar em que medida a organização prescrita e as condições de trabalho dos frentistas possibilitam construir um quadro elucidativo das origens da rotatividade na instituição estudada. $O$ pressuposto de base é que o fenômeno da rotatividade é por definição multicausal; portanto a lógica de funcionamento que estrutura a concepção formal do trabalho e orienta as atividades dos sujeitos pode contribuir decisivamente na gênese da rotatividade de pessoal.

O presente estudo inscreve-se no campo das pesquisas voltadas para as investigações de variáreis constituintes do serviço de atendimento ao público, em particular nas disciplinas de administração (marketing), psicologia (social e organizacional) e sociologia. A presente abordagem situa-se especificamente em uma linha de pesquisa nascente, intitulada Ergonomia do Serviço de Atendimento ao Público, em desenvolvimento no Laboratório de Ergonomia da Universidade de Brasília. A perspectiva analítica, cuja matriz é a ergonomia francofônica, centra-se na análise de situações reais de atendimento, cujos indicadores críticos constituem apenas portas de entrada para estudar as suas causas mais profundas.

O estudo da temática é relevante por diferentes motivos. Do ponto de vista acadêmico, as pesquisas são ainda incipientes e tendem a focalizar variáveis pontuais do contexto de atendimento (por exemplo, satisfação dos clientes, layout do setting de atendimento), veiculando uma perspectiva analítica reducionista. No campo da ergonomia, o recorte da temática como objeto de investigação é ainda precoce (Falzon e Lapeyrière, 1998). Do ponto de vista social, a aplicabilidade dos resultados das pesquisas pode contribuir para aprimorar a qualidade dos serviços prestados, reduzindo os problemas freqüentes que deterioram a relação cidadão-empresa e, desta forma, reforçar os direitos dos consumidores. Do ponto de vista organizacional, a implementação das recomendações e a sua avaliação periódica podem contribuir para atenuar e/ou suprimir os problemas constatados, construindo um contexto de atendimento em que todos, funcionários, usuários e organização, podem viabilizar os seus objetivos específicos.

O estudo tem origem na constatação da prática da rotatividade sistemática na função de frentista em uma rede de postos de abastecimento. Resultados de um 
projeto realizado pela empresa, voltado para a reorientação do processo seletivo e a composição de equipe ideal, mostraram que, das 94 demissões efetuadas no período de apenas um mês (agosto de 1999), cerca de 81\% ( $\mathrm{n}=77)$ foram na função de atendente. $\mathrm{O}$ argumento pivô, buscando justificar as causas do fenômeno, aparece centrado na idéia de inadaptabilidade do funcionário.

A análise ergonômica do trabalho dos frentistas realizou-se em um posto da rede, com base em dois recortes analíticos: (1) a concepção organizacional da função ou trabalho prescrito; (2) as atividades dos atendentes no cenário real de execução das tarefas. As seguintes questões orientaram a análise dos recortes adotados: qual é a concepção organizacional que preside o perfil formal do exercício da função? Quais são as características das tarefas prescritas para os frentistas? Quais são os traços implícitos da carga de trabalho, veiculados pelas tarefas? Em que consiste o processo de trabalho dos frentistas? Como se caracterizam as exigências reais da atividade de atendimento? Quais são os riscos inerentes à atividade dos frentistas e suas conseqüências?

As respostas às questões buscam, de um lado, identificar a lógica organizacional, que estrutura o modo de ser habitual da empresa e, de outro, a lógica do atendente, que orienta o modo operatório usual nas situações de trabalho.

\section{Quadro Teórico de Referência para o Estudo da Temática}

A delimitação do problema pontual de investigação deste estudo, com base na análise da demanda, definiu implicitamente as categorias teóricas principais que foram utilizadas na investigação ergonômica para a análise e a interpretação dos dados.

\section{Serviço de Atendimento ao Público: Ponto de Confluência de Diferentes Lógicas}

O trabalho dos frentistas situa-se em um contexto do serviço de atendimento ao público. Nesse cenário contracenam diferentes interlocutores, onde os elementos de cenografia aparecem definidos a priori pela empresa (equipamentos, instrumentos, espaço), e as regras da interação dos sujeitos são preestabelecidas pela organização do trabalho (Ferreira, 1999).

As linhas gerais da abordagem teórica em ergonomia do serviço de atendimento ao público foram objeto de análise em outro trabalho (Ferreira, 200_). O 
atendimento é definido como atividade complexa e mediadora, que coloca em cena a interação social de diferentes sujeitos em contexto específico, visando a responder a distintas necessidades.

A partir desta perspectiva teórica, alguns estudos realizados (Ferreira, Carvalho e Sarmet, 1999; Gonçalves e Ferreira, 1999) mostram que o serviço de atendimento ao público é resultante da sinergia de multivariáveis: a conduta do usuário, as atividades dos funcionários envolvidos na situação, a organização do trabalho e as condições físico-ambientais/instrumentais. Essas variáveis funcionam como propulsores da dinâmica de atendimento, com base nas mudanças internas e externas das situações de atendimento e de regulações permanentes.

O diagnóstico dos problemas existentes implica descodificar três lógicas: (1) a lógica da instituição, identificando os fatores (processos organizacionais e suportes disponibilizados) que caracterizam o modo de ser habitual da instituição; (2) a lógica do atendente, analisando os fatores (perfil individual, competência profissional e estado de saúde) que caracterizam o modo operatório usual do atendente, estruturadores da conduta nas situações de atendimento; (3) a lógica do usuário, analisando os fatores (perfil socio-econômico e representação social) que caracterizam o modo de utilização dos serviços pelos usuários e o seu comportamento no atendimento.

O serviço de atendimento é abordado como ponto de confluência dessas diferentes lógicas. Os desequilíbrios e incompatibilidades existentes entre as lógicas se manifestam sob a forma de indicadores críticos (tempo de espera, reclamações dos usuários, erros, insatisfação dos atendentes etc.). É na análise da interface da atividade dos funcionários com o comportamento do usuário que são investigados os elementos explicativos da emergência dos fatores críticos existentes e os seus efeitos para os funcionários, usuários e instituição. No presente caso, esta interface constitui o centro da análise para investigar a inter-relação da carga de trabalho do frentista com a prática da rotatividade sistemática.

\section{Rotatividade de Pessoal: Ponta do Iceberg do Mal-Estar Organizacional}

O fenômeno da rotatividade revela-se fonte de preocupação das empresas em um cenário de competição globalizada. Nesse contexto, a competitividade implica oferecer qualidade de serviços e produtos, reforçando a importância da política de administração de pessoal que possibilite a permanência de profissionais na empresa, desenvolvendo trabalhos com eficiência e eficácia. Assim, a ocorrência da rotatividade pode ser a ponta do iceberg de distorções na política de recursos humanos. 
Na literatura brasileira, conforme levantamento, a temática da rotatividade aparece ainda de modo residual (Chiavenato, 1995). De fato, os índices mensais e anuais de rotatividade na prática das organizações brasileiras são habitualmente calculados, mas permanecem como objeto de contemplação, sem despertar grande interesse dos pesquisadores. Em contrapartida, nos Estados Unidos, por exemplo, o turnover tem sido objeto de análises mais freqüentes. Nesse sentido, dois aspectos têm-se destacado: as causas e as conseqüências.

As causas são múltiplas. De modo geral, os fatores mais mencionados na literatura são a política salarial adotada pela empresa; a política de benefícios, oportunidades de progresso profissional oferecidas pela empresa; tipo de supervisão; a política disciplinar; as condições físicas ambientais de trabalho; a motivação do pessoal. Todavia, conforme o autor, a ênfase varia. Por exemplo, Brannick (1999) afirma que a rotatividade se manifesta em função principalmente dos seguintes fatores: a relação deficiente entre o funcionário e a cultura organizacional; o treinamento inadequado; a falta de incentivos; as políticas organizacionais. Enquanto para Epstein (1999), a maioria dos gerentes acredita que o salário é a grande preocupação dos trabalhadores, negligenciando o fato de que as pessoas necessitam de outros fatores de compensação.

Os custos da rotatividade de pessoal podem ser significativos, abrangendo desde a queda da produtividade até a perda de historicidade da instituição, que parece também demitida com os veteranos que partem. O impacto sobre os consumidores e os custos trabalhistas são duas conseqüências salientadas na literatura. Entre os caminhos para a redução dos altos índices de rotatividade são apontadas providências nos seguintes campos: (1) melhoria do ambiente de trabalho; (2) análise do desempenho dos supervisores e das práticas de compensação; (3) boa integração com os funcionários, oferecendo-lhes condições de progresso dentro da empresa.

A rotatividade de pessoal, neste estudo, é analisada com base no referencial teórico da ergonomia, em particular com a identificação da carga de trabalho dos frentistas como resultante da discrepância entre trabalho prescrito e trabalho real.

\section{Duas Dimensões do Trabalho: o Prescrito e o Real como Vetores da Carga de Trabalho}

A produção teórica em ergonomia tem como um de seus pilares a distinção entre trabalho prescrito (teórico, formal) e trabalho real (efetivo, em situação) como dimensões centrais para se compreenderem os disfuncionamentos que se manifestam nas organizações. Essa distinção, enfatizada pela ergonomia 
francofônica, foi construída teoricamente a partir de inúmeras intervenções em diferentes contextos sociotécnicos e aparece na literatura freqüentemente associada com outra noção complementar, a carga de trabalho.

A ergonomia mostra que a noção de trabalho prescrito tem sua origem na administração científica do trabalho (Taylor, 1987), que busca estabelecer a maneira como o trabalho deve ser executado (modo de utilizar as ferramentas e equipamentos), o tempo previsto para as operações, os modos operatórios e as regras por respeitar (Laville, Teiger e Daniellou, 1989). A noção de trabalho prescrito comporta duas dimensões complementares: (1) trabalho teórico lato sensu, constituído pelas representações sociais, habitando os pontos de vista dos diferentes sujeitos na esfera da produção (do operário ao diretor-presidente); e (2) tarefas previstas, circunscritas num contexto sociotécnico particular, evidenciando os braços invisíveis da organização do trabalho que fixa as regras da produção.

Em ergonomia, o estudo do trabalho prescrito privilegia a análise das tarefas. A tarefa pode ser definida como objetivo dado em condições determinadas, para um sujeito determinado (Leplat, 1983). O exame da literatura em ergonomia possibilita depreender os traços característicos que acompanham a noção de tarefa como ferramenta imprescindível na análise do trabalho: (1) a tarefa é preexistente ou anterior à atividade; (2) ela é resultante da concepção formal ou informal de quem determina a execução do trabalho; (3) a descrição de tarefa veicula explícita ou implicitamente um modelo idealizado de sujeito; (4) toda a tarefa requer do sujeito uma dupla atividade: elaboração e execução.

Por sua vez, a noção de trabalho real é construída em termos da atividade dos operadores e ocupa um lugar hierárquico central no estudo do trabalho. A atividade sintetiza e integra os diferentes fatores que estruturam o processo de trabalho (Guérin et al., 1997). É na situação real de trabalho que a atividade dá visibilidade aos determinantes que condicionam a sua interação com o meio.

O uso da noção de atividade em ergonomia aparece freqüentemente entendida como processo incessante de construção pelos sujeitos de estratégias e modos operatórios para responder às exigências do trabalho prescrito. Nesta direção, a atividade pode ser definida como processo de regulação permanente do sujeito para "tentar manter o equilíbrio com a sua situação e o seu ambiente de trabalho, de modo a obter os resultados esperados dentro das melhores condições possíveis" (Weill-Fassina, 1990). Dois aspectos são importantes nesse enfoque da atividade: a imprevisibilidade da atividade, que vai exigir do trabalhador, a cada instante, uma inteligência criadora; e o fato de que o eixo da atividade coloca em primeiro plano o conhecimento e o savoir-faire dos operadores, como fator inesgotável para garantir o que a empresa espera alcançar (Ferreira, 1998). 
Em síntese, o enfoque do trabalho real neste estudo comporta a atividade do sujeito, seu modus operandi em um contexto sociotécnico específico, que colocam em cena o seu corpo, a sua experiência e a sua afetividade para responder às lacunas do trabalho prescrito.

Assim, tanto o trabalho prescrito quanto a atividade real veiculam implicitamente um custo humano do trabalho, que é abordado em ergonomia em termos de carga de trabalho. O conceito de carga de trabalho não é território de consenso em ergonomia; ele aparece marcado por controvérsias, ambigüidade e imprecisão (Ferreira e Marcellin, 1985; Brito, 1991; Moraes e Mont'Alvão, 1998). Em geral, a noção de carga de trabalho aparece associada a dois aspectos: (1) as variáveis presentes na situação de trabalho agem de modo combinado e causam impacto no operador, exigindo dele um esforço permanente de regulação e adaptação; tal esforço não é indolor, a regulação é acompanhada de desgaste, de custo para o sujeito (Laurell e Noriega, 1989); e (2) a função mediadora da carga para compreender a inter-relação trabalho-desgaste vivenciada pelos operadores.

A carga de trabalho, para as finalidades deste estudo, é definida pela interrelação entre as exigências externas, ambientais, instrumentais, organizacionais, impostas ao operador, exigindo dele estratégias de regulação para garantir os objetivos prescritos pela organização, desenvolver a sua competência profissional e preservar o seu bem-estar. Nessa perspectiva, a noção de carga está intimamente articulada a duas dimensões interdependentes: as exigências externas (contraintes) capitaneadas pelas tarefas, e os efeitos percebidos pelos sujeitos (astreintes) destas exigências externas.

O conceito de carga de trabalho pode ser, didaticamente, abordado a partir de três componentes interligados: o físico, o cognitivo e o psíquico. Toda a carga de trabalho é portadora destes três componentes, ou seja, a sobrecarga produzida em qualquer um deles repercute nos demais (Wisner, 1987). Assim, mesmo uma atividade aparentemente simples cobra do operador um exercício mental considerável e insubstituível, para garantir o funcionamento do sistema produtivo e atender aos limites inerentes à prescrição do trabalho. Enfim, esse recorte tem a vantagem de facilitar a análise da conduta dos sujeitos em trabalho, visando a responder às exigências externas; mas é importante enfatizar que tal separação é apenas um recurso instrumental para analisar a carga de trabalho, nesse caso dos frentistas. 


\section{Abordagem Metodológica para a Investigação da Temática}

A abordagem metodológica adotada no estudo é a Análise Ergonômica do Trabalho - AET (Montmollin, 1990; Laville, 1993). Esta abordagem (vide Figura 1) baseia-se no modelo elaborado por Guérin et al. (1997), cuja característica central consiste na flexibilidade procedimental na evolução das etapas. Ela tem como pressupostos: (1) a participação voluntária dos sujeitos envolvidos na intervenção ergonômica; e (2) a investigação do trabalho nas situações reais onde este se inscreve. Nesse sentido, o produto da AET se caracteriza como uma coprodução, tendo como horizonte garantir o bem-estar dos sujeitos e a eficiência e eficácia do processo produtivo.

\section{Figura 1: Análise Ergonômica do Trabalho - Etapas e Procedimentos Principais}

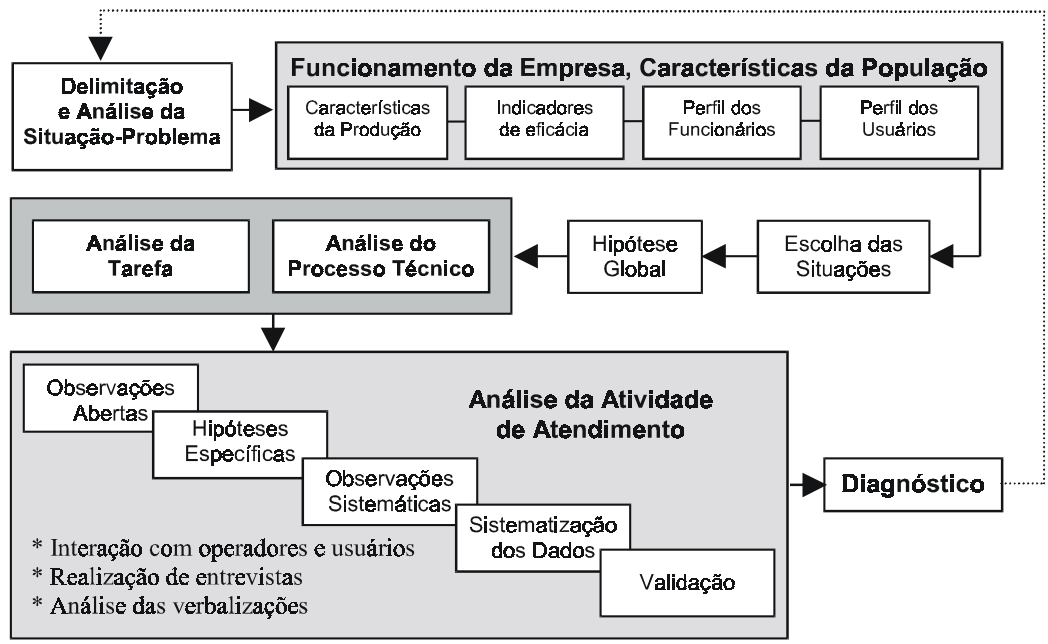

Fonte: adaptado de Guérin et al. (1997, p.129).

\section{Participantes}

Participaram do estudo: (1) oito frentistas do posto de abastecimento $(\mathrm{N}=14)$ com o seguinte perfil: sexo masculino; idade variando de 21 a 32 anos; a maioria com $1^{\circ}$ grau completo e com a média de oito meses de tempo de serviço na empresa; e (2) trinta usuários do posto ( $\mathrm{N}=250$ /dia) com o seguinte perfil: a maioria do sexo masculino e com nível superior de escolaridade, idade variando de 18 a 73 anos. 


\section{Instrumentos e Procedimentos}

Para o levantamento de dados utilizaram-se instrumentos característicos da AET, com base em procedimentos específicos.

Análise Documental. O objetivo foi identificar os fatores macro (por exemplo, finalidades institucionais) e microorganizacionais (por exemplo, tarefas prescritas e suporte previsto) que serviram para a compreensão da situação-problema. Analisaram-se documentos sobre a concepção do trabalho prescrito para a função de atendente.

Observação Livre. Foram dois os objetivos: realizar os primeiros contatos com os funcionários e estabelecer uma visão panorâmica do trabalho e das condições em que é realizado na situação estudada. Ela ocorreu durante a jornada de trabalho, em dias alternados, perfazendo um total aproximado de seis horas.

Observação Sistemática. Os objetivos foram identificar e contextualizar os modos operatórios dos sujeitos em função das exigências do trabalho e da evolução das situações. Foi realizada no turno matutino, com o suporte de um gravador, perfazendo um total de dezesseis horas de observação.

Entrevistas Semi-Estruturadas Individuais. Os objetivos foram múltiplos: (1) identificar as estratégias cognitivas de trabalho dos sujeitos; (2) validar os dados coletados, sobretudo os oriundos da observação sistemática; (3) levantar informações com os clientes sobre o serviço de atendimento. Elaborou-se um roteiro com base nos dados da observação e da análise documental realizadas na empresa, conforme a disponibilidade dos sujeitos.

Com base em enfoque qualitativo, os dados coletados foram tratados e sistematizados sob a forma de esquemas, de fluxos do processo de trabalho e quadros descritivos do trabalho prescrito e dos componentes da carga de trabalho.

\section{Resultados e Discussão}

Os resultados do estudo são apresentados em duas partes complementares: (1) a dimensão prescrita do trabalho, buscando identificar as suas características principais, as tarefas previstas e os componentes implícitos da carga de trabalho; (2) a dimensão real do trabalho, visando a identificar os aspectos que marcam a atividade dos frentistas para responder às exigências das tarefas e às condições de trabalho existentes e como eles percebem a função. 


\section{Concepção do Trabalho de Frentista: da Prescrição do Elogio às Punições Previstas}

O documento da empresa intitulado Normas sobre a Conduta Profissional dos Atendentes foi a fonte empírica para a análise do trabalho prescrito.O seu exame possibilitou identificar o perfil do frentista e de suas tarefas.

\section{Traços Gerais das Normas de Conduta Profissional dos Atendentes}

As normas estão organizadas em tópicos específicos que ditam as regras de conduta dos atendentes (vide Figura 2). A sua finalidade é regular as atividades do atendente: "estimulando-o e desenvolvendo-o profissionalmente no que se refere à disciplina, apresentação individual, assiduidade, pontualidade, dedicação ao trabalho e quanto a sua formação ética e moral na prestação de serviço ao cliente" (sem grifo no original). Nesse sentido, o documento veicula um ponto de vista sobre o trabalhador e o trabalho; uma ideologia administrativa que idealiza o atendente em termos de como ser e de como fazer ${ }^{(1)}$.

\section{Figura 2: O Trabalho Prescrito - Estrutura das Normas sobre Conduta Profissional dos Atendentes}

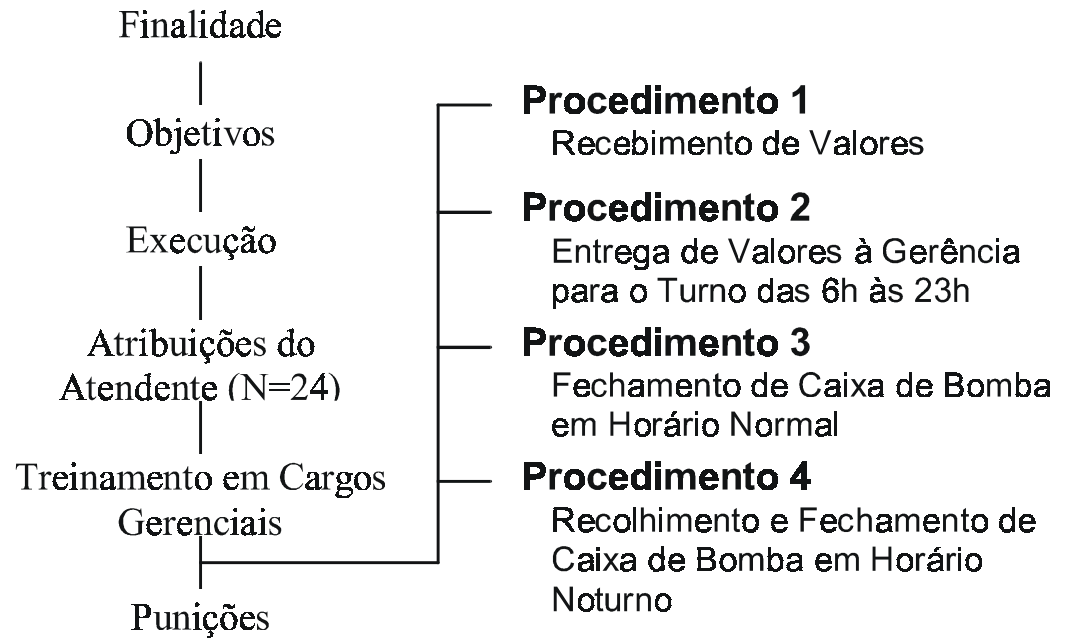

As normas visam a desenvolver no atendente o espírito de equipe, criando um clima de confiança e buscando a melhoria contínua do serviço. O texto assinala claramente que o seu objetivo é "adaptar o atendente para a observância e acatamento das normas e instruções que fundamentam as relações profissio- 
nais na empresa" (sem grifo no original). Assim, a finalidade e os objetivos manifestos indicam uma concepção administrativa que transcende as habituais práticas administrativas de análise e descrição de cargos, para estabelecer uma espécie de código de conduta do funcionário.

As normas prevêem regras e ações específicas para a sua operacionalização, cabendo destacar a realização de curso de Orientação aos Novos Funcionários, com duração de cinco dias, cujo objetivo é treinar os atendentes para o "perfeito entendimento das condições de trabalho, normas e instruções da empresa e da prestação de serviço" (sem grifo no original). No período de experiência, prevê-se o fiel cumprimento das normas, e a conduta do atendente é monitorada por um supervisor, que deve preencher uma ficha de acompanhamento. No término desse período, o funcionário deve entregar ao supervisor um documento, cujo título Relatório de Adaptação ao Serviço reforça a ideologia administrativa fundada no objetivo organizacional de adaptar o sujeito à organização.

Além desses traços gerais, que caracterizam as normas da organização, o documento dedica-se a prescrever as atribuições e os procedimentos que devem ser cumpridos fielmente pelos atendentes e as punições previstas para as faltas que eles possam cometer.

\section{Conduta Prescrita do Frentista: Tarefas e Punições}

As atribuições prescritas $(\mathrm{n}=24)$ contemplam muitos aspectos do trabalho. Nesse sentido, as tarefas prescrevem ações em diferentes campos: (1) nas relações sociais do frentista na interação com os clientes, colegas e hierarquia; (2) no manuseio de produtos e equipamentos de trabalho; (3) na prestação dos serviços e venda de produtos; (4) no recebimento, registro e controle contábil das operações realizadas; mas o perfil prescrito da função não se restringe a esses aspectos.

As atribuições ditam, ainda, regras que traçam, além dos comportamentos desejáveis no controle do seu desempenho (por exemplo, obrigação da pontualidade), a própria apresentação pessoal (por exemplo, o frentista deve manter-se limpo, barbeado, com cabelos cortados e penteados, sapatos engraxados). Nesse caso, constata-se que a concepção prescrita busca não só definir o que e o como fazer, mas também o como estar dos frentistas.

A análise das tarefas permitiu também identificar as diferentes exigências que elas veiculam, possibilitando inferir as distintas dimensões da carga de trabalho implícitas na função de frentista em relação às suas exigências predominantes. Nesse aspecto, o desempenho da função requer implicitamente habilidades cognitivas específicas para responder às exigências de tratamento de informações; 
esforços biomecânicos (posturas, gestos e movimentos) para executar o trabalho manual e capacidade de interação social para atender às demandas de diferentes interlocutores (clientes, colegas, chefias). Nesse último aspecto, o ideólogo da organização do trabalho curiosamente prescreve para os frentistas a obrigação do elogio como tarefa (vide Quadro 1).

\section{Quadro 1: Exemplos de Tarefas e Predominância de Exigências em Diferentes Dimensões da Carga de Trabalho}

\begin{tabular}{|c|c|c|c|}
\hline & Dimensão Física & Dimensão Cognitiva & Dimensão Psíquica \\
\hline 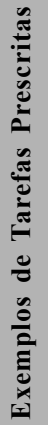 & $\begin{array}{l}\text { - Cuide dos jardins, banheiros, } \\
\text { pista, lixeiras, meios-fios, } \\
\text { esgotos, estantes, grades, } \\
\text { ilhas, freezer, placas } \\
\text { indicativas, bombas. } \\
\text { - Mantenha os produtos } \\
\text { arrumados, limpos e expostos } \\
\text { nos devidos lugares. } \\
\text { - Permaneça sempre de frente } \\
\text { ou ao lado das bombas. }\end{array}$ & $\begin{array}{l}\text { - Certifique-se do combustível } \\
\text { a ser fornecido. } \\
\text { - Acompanhe o abastecimento, } \\
\text { não deixando o combustível } \\
\text { derramar. } \\
\text { - Anote o valor depositado na } \\
\text { Ficha de Controle de } \\
\text { Recolhimento de Numerário. } \\
\text { - Preencha a folha de ponto } \\
\text { conforme as instruções } \\
\text { estabelecidas. }\end{array}$ & $\begin{array}{l}\text { - Aborde, recepcione } \\
\text { gentilmente e oriente o } \\
\text { cliente. } \\
\text { - Atenda às reclamações dos } \\
\text { clientes. } \\
\text { - Busque a integração da } \\
\text { equipe. } \\
\text { - Elogie o companheiro, } \\
\text { quando estiver fazendo um } \\
\text { bom trabalho. } \\
\text { - Obedeça às instruções do } \\
\text { gerente. }\end{array}$ \\
\hline
\end{tabular}

É importante ressaltar que a concepção do trabalho prescrito surge fortemente associada aos procedimentos administrativos de punição, que aparecem detalhadamente explicitados no documento analisado (vide Quadro 2, a seguir).

Nesse contexto, a punição é um ingrediente intimamente articulado às tarefas. O uso do recurso da pena revela a opção formal escolhida pela organização para desenvolver a disciplina, a formação ética e moral para adaptar o frentista ao trabalho.

\section{Multifunções do Frentista e Exigências Cognitivas das Tarefas}

O exame do trabalho prescrito parece indicar não somente uma função do frentista, mas a existência de múltiplas funções. Nesse sentido, a concepção formal da organização ambiciona um funcionário que desempenhe distintos papéis, que transcendem de longe o senso comum do frentista como "alguém que apenas executa o abastecimento de combustível".

Algumas passagens das normas servem de indícios empíricos da afirmação precedente: função de faxineiro (por exemplo, as tarefas de limpeza e asseio); 
função de vendedor (por exemplo, a venda de produtos do posto); função de escriturário (por exemplo, o preenchimento de notas fiscais, documentos contábeis); função de policial (por exemplo, coibir a presença de pessoas estranhas no posto, sobretudo de vendedores ambulantes); e, principalmente, a função de caixa (por exemplo, o recebimento, registro e controle de valores monetários). Essa última função é amplamente dominante na concepção do papel do frentista, pois, além das atribuições gerais, as normas estabelecem regras pontuais no manuseio de valores.

\section{Quadro 2: Tipos de Falta e Punições Previstas nas Normas da Organização}

\begin{tabular}{|c|c|c|}
\hline Tipo de Falta & Exemplo de Prescrição & Punições Cabíveis \\
\hline $\begin{array}{l}\text { - Higiene Pessoal } \\
\text { - Atraso no Início da Jornada } \\
\text { - Absenteísmo } \\
\text { - Recusa de Pegar Caixa } \\
\text { - Não Preenchimento da } \\
\text { Ficha de Controle de } \\
\text { Numerário } \\
\text { - Preenchimento Incorreto da } \\
\text { Folha de Ponto } \\
\text { - Não Assinatura do Recibo } \\
\text { de Vale Transporte }\end{array}$ & $\begin{array}{l}\text { "O atendente deverá manter- } \\
\text { se limpo e com boa } \\
\text { aparência, sem barba, bigode } \\
\text { ou costeleta, cabelos cortados } \\
\text { e penteados, com sapatos } \\
\text { engraxados, usando o } \\
\text { uniforme da empresa e } \\
\text { portando crachá de } \\
\text { identificação". }\end{array}$ & $\begin{array}{l}\text { Procedimento 1: } \\
\text { 1. Advertência Verbal } \\
\text { 2. Advertência por Escrito } \\
\text { 3. Suspensão por Escrito } \\
\text { 4. Dispensa por Justa Causa }\end{array}$ \\
\hline $\begin{array}{l}\text { - Ausência no Serviço aos } \\
\text { Domingos e Feriados } \\
\text { - Cheques Devolvidos } \\
\text { - Operações de Troca de } \\
\text { Cheque ou Cartão de } \\
\text { Crédito/Débito por Dinheiro } \\
\text { - Assinatura do Recibo de } \\
\text { Vale Transporte }\end{array}$ & $\begin{array}{l}\text { "O atendente que não cumprir } \\
\text { a norma de recebimento de } \\
\text { cheque, conforme descrito no } \\
\text { 'Procedimento 1' e tiver como } \\
\text { conseqüência a devolução de } \\
3 \text { cheques dentro do espaço } \\
\text { de } 1 \text { mês, será punido pelo } \\
\text { gerente". }\end{array}$ & $\begin{array}{l}\text { Procedimento 2: } \\
\text { 1. Advertência por Escrito } \\
\text { 2. Suspensão por Escrito } \\
\text { 3. Dispensa por Justa Causa }\end{array}$ \\
\hline - Furo de Caixa & $\begin{array}{c}\text { "Todo o atendente que não } \\
\text { pagar no ato do fechamento } \\
\text { do caixa ou após cobrança } \\
\text { do gerente, a diferença que } \\
\text { porventura ocorrer, acima de } \\
\text { R } \$ 10,00 \text { (dez reais) será } \\
\text { punido". }\end{array}$ & $\begin{array}{l}\text { Procedimento 3: } \\
\text { 1. Advertência por Escrito } \\
\text { 2. Suspensão por Escrito de } \\
3 \text { dias } \\
\text { 3. Suspensão por Escrito de } \\
5 \text { dias } \\
\text { 4. Dispensa por Justa Causa }\end{array}$ \\
\hline
\end{tabular}

A função de caixa expressa (vide Figura 3), de forma mais evidente, a predominância das exigências cognitivas no trabalho de frentista, na medida em que 
ele deve executar procedimentos administrativos específicos no recebimento/ entrega de valores e no fechamento do caixa (vide procedimentos na Figura 2).

\section{Figura 3: Procedimentos e Informações Prescritas no Recebimento de Valores em Cheque pelo Atendente}

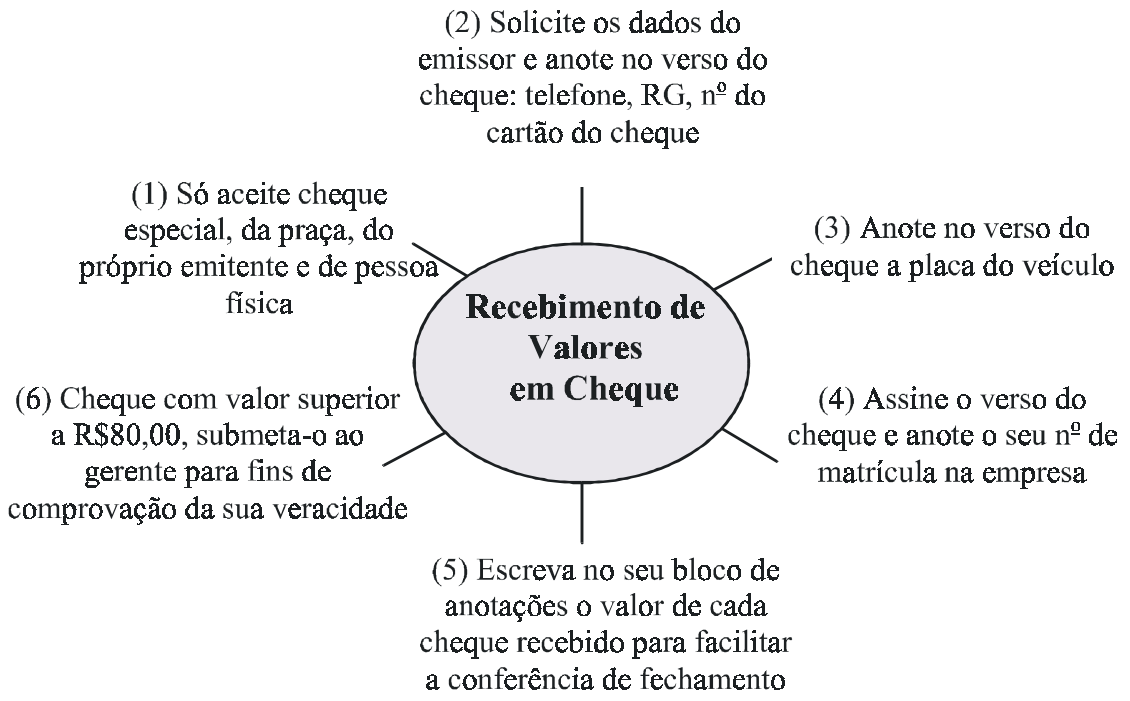

O pagamento em cheque pelo cliente ilustra a carga informacional a ser tratada, passo a passo, para prevenir erros e retrabalho e, desta forma, evitar as punições que pairam sobre a cabeça do atendente. Por último, cabe salientar que a centralidade do papel de caixa do frentista é reforçada pelo destaque nas normas da punição prevista para a ocorrência de furo de caixa (vide Quadro 2).

\section{O Trabalho Real do Frentista: da Rotina aos Indicadores da Complexidade no Trabalho}

A análise da atividade, validada e enriquecida pelas entrevistas dos frentistas, forneceu elementos empíricos para construir o cenário característico, onde se efetiva o ritual do exercício da função.

\section{Traços Gerais da Atividade de Atendimento dos Frentistas}

Uma jornada típica de trabalho dos frentistas compreende essencialmente três momentos distintos: (1) atividades de início de jornada (por exemplo, assinatura da folha de ponto); (2) atividades de atendimento dos clientes (por exemplo, abaste- 
cimento de combustível); (3) atividades de encerramento da jornada (por exemplo, fechamento do caixa de bomba). A atividade de atendimento dos clientes pode ser resumida nos seguintes tipos de ação:

. abordagem do cliente, solicitando informações sobre o serviço desejado;

. zeramento da bomba e acionamento do mecanismo de abastecimento automático da bomba;

- consulta ao cliente para saber se ele deseja a realização dos serviços de limpeza do pára-brisa e faróis do veículo;

. retirada da mangueira da bomba, após alarme acionado automaticamente, indicando a conclusão do abastecimento;

- informação ao cliente e recebimento do valor do produto, que pode ser feito em três formas de pagamento: dinheiro, cheque ou cartão de crédito;

. execução de procedimentos administrativos específicos em função da modalidade de pagamento escolhida pelo cliente;

- fechamento do caixa de bomba, ao término do turno, anotando os valores recebidos na Ficha de Controle de Recolhimento de Numerário.

Assim, o centro das atividades dos frentistas, confirmando uma inferência na análise do trabalho prescrito, não se encontra no papel de vendedor como se poderia imaginar inicialmente, mas predominantemente na função de caixa. Os frentistas passam a maior parte da jornada executando atividades de recebimento, registro, depósito de valores e de contabilização de caixa (vide Figura 4, a seguir). A importância dessas atividades se fundamenta sobretudo nos riscos que lhes são inerentes (por exemplo, receber uma quantia inferior ao valor do produto vendido) e respectivas punições estabelecidas pelas normas (por exemplo, advertência por escrito em função de um cheque devolvido), como também nas exigências cognitivas no tratamento de informações alfanuméricas que habitam as diferentes operações de venda (por exemplo, preencher corretamente a nota fiscal).

Os depoimentos dos frentistas revelam dois aspectos que parecem marcar a evolução de competências no desempenho da função: (1) para os frentistas debutantes (em geral com até 60 dias na função), a dificuldade maior consiste em aprender a manusear a bomba de combustível; (2) para os frentistas mais experientes (em geral, acima de 60 dias e até um ano na função), a dificuldade maior reside em gerir a função de caixa e interagir com os clientes. 


\section{Figura 4: Fluxo das Principais Etapas da Atividade de Atendimento dos Frentistas}

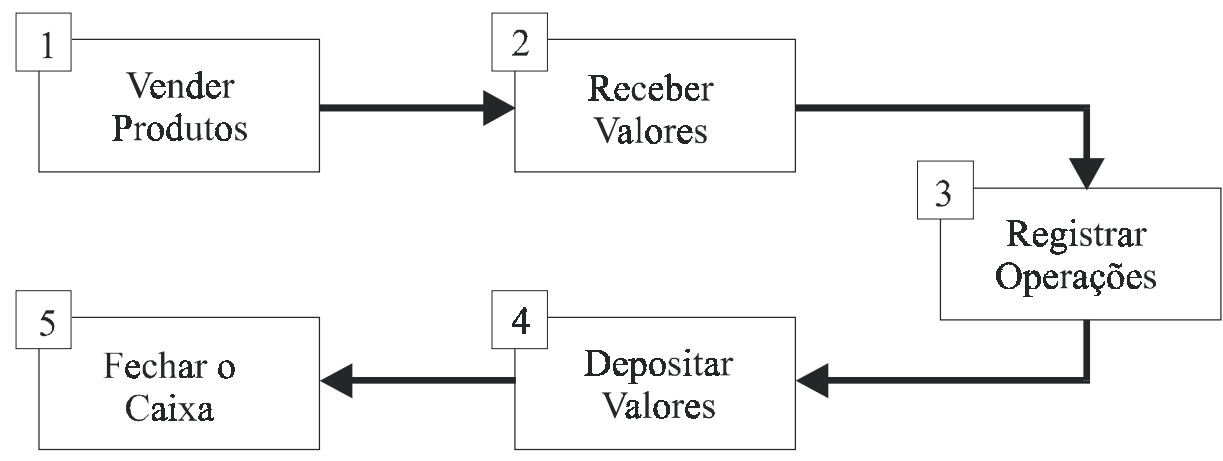

Um zoom nas etapas que caracterizam o fluxo habitual das atividades dos frentistas (vide Figura 4), permitiu identificar as exigências efetivas que marcam esse tipo de trabalho. Tais exigências dão visibilidade aos componentes físico, cognitivo e psíquico, que configuram a carga de trabalho típica dos atendentes.

\section{Conduta Efetiva do Frentista: As Múltiplas Exigências do Trabalho}

O cruzamento de dados resultantes das observações e das entrevistas mostra os aspectos mais críticos que agregam dificuldades ao desempenho da função, que são apresentados, a seguir, com base nos componentes da carga de trabalho.

Do ponto de vista físico, o fator que se destaca é a queixa dos frentistas de ter que trabalhar em pé: o custo biomecânico mais intenso do trabalho resulta principalmente da posição do corpo que, não obstante o caráter dinâmico da atividade, deve permanecer durante toda a jornada na postura de pé. Nesse caso, os frentistas buscam não só atender às múltiplas exigências da atividade, mas operacionalizar uma regra ditada pelo prescrito: "permaneça sempre em frente ou ao lado das bombas". Quanto às tarefas prescritas de limpeza e asseio, constatou-se, durante as observações, que elas são, a rigor, residuais nas atividades dos frentistas, situando-se mais no plano da formalidade.

Nesse contexto, as reclamações dos frentistas sobre o trabalho em pé foram praticamente consensuais nas verbalizações: "ficar em pé é muito cansativo. É a pior coisa."; "é ruim, chego a ficar sete horas aqui. Quando é o caso de dobrar o turno, chego a ficar até 15 horas em pé". Tais queixas são compreensíveis, pois a literatura em fisiologia do trabalho mostra que a posição de pé constitui fonte de fadiga corporal freqüente, exigindo intenso trabalho da musculatura responsável 
pela manutenção dessa posição. Nesse tipo de exigência postural, aumenta consideravelmente o esforço do coração para bombear o sangue para as extremidades do corpo, a fim de garantir o funcionamento muscular ${ }^{(2)}$.

Do ponto de vista psíquico, a atividade dos frentistas aparece marcada por distintas exigências que acentuam a carga de trabalho, possibilitando inferir a existência de um contexto socio-organizacional peculiar de vivências de prazersofrimento no trabalho. No caso estudado, as relações sociais de trabalho, combinadas com a necessidade de atender às regras da organização do trabalho, constituem o fator de desgaste mais expressivo nas atividades dos frentistas. Tais relações sociais de trabalho são vivenciadas na interação com três tipos de interlocutores principais: os clientes, os colegas e as chefias.

Todavia, é na relação com os clientes que reside a fonte principal de desgaste e queixas dos frentistas. A postura do cliente é determinante para deteriorar a interação, e os exemplos são diversos: a irritação, a pressa, a desconfiança, a resistência em entregar documentação pessoal e as reclamações freqüentes dos clientes são aspectos que apareceram recorrentemente nas verbalizações dos sujeitos: "tem uns clientes que são difíceis. Se você pergunta até sobre o combustível ele se zanga"; "o difícil é ouvir sapo dos clientes". Os dados das entrevistas com a clientela apontam majoritariamente uma rejeição quanto à possibilidade de aumentar o tempo de atendimento em função dos procedimentos de conferência dos documentos no pagamento em cheque.

Não é raro o cliente atribuir o atraso na cobrança do serviço ao frentista, quando de fato tal atraso ocorre, por exemplo, pelo funcionamento ineficiente do sistema de consulta de cartão, uma vez que o sistema demora a responder ao tratamento contábil solicitado. Assim, em função da situação potencialmente explosiva que caracteriza o contexto de atendimento, os frentistas buscam desenvolver modos operatórios de enfrentamento para garantir a qualidade do trabalho e preservar o seu bem-estar psíquico; por exemplo, um frentista que adota uma regra pessoal do tipo "eu evito amolar o cliente".

Do ponto de vista cognitivo, a atividade dos frentistas se caracteriza por exigências dinâmicas e diferenciadas. Elas são oriundas principalmente da natureza das tarefas prescritas, das condições efetivas de trabalho e, sobretudo, do papel multifuncional que o frentista deve desempenhar para atender às normas da organização. Assim, a análise da atividade mostra um conjunto de fatores que aumenta consideravelmente o esforço cognitivo. Tais fatores são de naturezas distintas, como se discriminam em seguida.

- Características dos veículos. Por exemplo, é importante diagnosticar corretamente o tipo de tanque do veículo; em carros mais antigos, pode ocorrer o 
retorno de combustível, exigindo atenção redobrada do frentista para não danificar a pintura. $\mathrm{Ou}$, ainda, a variabilidade dos modelos de carro: um atendente relata "o cara pediu para botar óleo em um carro importado. Eu não sabia onde ficava o motor e ele riu de mim".

- Funcionamento dos equipamentos. Por exemplo, o frentista se vê obrigado a gerir os problemas decorrentes do funcionamento ineficiente do sistema de pagamento em cartão. Freqüentemente o sistema está fora do ar e/ou ocorrem congestionamentos em função da disponibilidade de apenas uma linha telefônica para responder às demandas. $\mathrm{O}$ atendente afirma: "o problema é quando o cartão demora a passar. Nesse caso, o cliente não entende que a culpa não é da gente".

- Especificidades das demandas dos clientes. Por exemplo, é crucial diagnosticar o tipo de combustível utilizado, visando a evitar erro e retrabalho. Nesse caso, constatou-se que, muitas vezes, a comunicação ineficiente entre clientefrentista produz dúvidas, levando os frentistas ao modo operatório de cheirar a tampa do tanque para certificarem-se do tipo de combustível existente. Um frentista observa: "de vez em quando, tem que dar uma cheiradinha no combustível para saber se é álcool ou não".

- Dinâmica da situação. Por exemplo, freqüentemente o tempo de atendimento é bastante reduzido devido à necessidade de rapidez por parte dos clientes, tornando impossível seguir à risca os procedimentos prescritos (por exemplo, solicitação da documentação completa do emissor do cheque). Os frentistas assinalam: "se for pedir todos os documentos, não dá tempo; a gente só registra mais a placa"; "demora demais, cria engarrafamento e o cliente fica zangado".

Assim, o trabalho mental dos sujeitos implica fundamentalmente tratar de forma adequada as informações disponíveis e tomar decisões apropriadas conforme as especificidades das situações de atendimento. Nesse contexto, as normas tendem a engessar a margem de manobra dos frentistas na regulação eficiente $e$ eficaz do recebimento de valores, pois eles precisam equacionar a ocorrência de incidentes críticos.

Desse modo, observa-se a configuração de um contexto onde o caráter predominantemente esquizo do trabalho prescrito agrega complexidade às atividades dos frentistas, exigindo um esforço pessoal significativo de adaptação em função das peculiaridades do dia-a-dia. Nesse caso, as punições previstas acrescentam um componente de agravamento na execução da atividade, introduzindo um fator de pressão e de tensão permanente, que dificulta a garantia da qualidade do trabalho. 


\section{Custo Pessoal da Função Caixa e o Paradigma Organizacional Cliente Sempre Tem Razão}

A função caixa, papel predominante dos frentistas, caracteriza-se por intensas exigências cognitivas dos sujeitos em função da quantidade e da variabilidade das informações a serem tratadas em um contexto dinâmico; por exemplo, pagamento com cartão de crédito. A interação de diferentes variáveis agrega complexidade ao trabalho mental para captar, armazenar, evocar e tratar múltiplas informações, visando a garantir a eficiência e eficácia da tarefa prescrita. Assim, a responsabilidade pelo caixa de bomba significa gerir, paralelamente, não só as exigências e as implicações inerentes à função, mas também os incidentes críticos que ocorrem durante a jornada, assumindo os riscos do furo de caixa que cotidianamente ameaçam a atividade.

Além deste traço marcante da atividade do frentista, a compreensão de seus efeitos se completa pelo casamento de dois aspectos que, agindo de modo combinado, parecem jogar papel fundamental para tornar um desafio insuportável a sua permanência na função:

- o risco permanente do furo de caixa transforma o frentista, tal qual o caixa bancário, no profissional entre zeros. Ele precisa conviver com a tensão diária de prevenir as diferenças negativas que se podem manifestar no fechamento. Os fracassos em zerar o caixa têm duas conseqüências para o frentista: a punição prescrita que coloca em risco o emprego e a obrigação de ressarcir financeiramente o prejuízo, sobretudo nos casos de devolução de cheques. Ora, isto significa para o frentista utilizar o próprio salário para pagamento de um risco inerente à atividade comercial.

- ao mesmo tempo, dois outros ingredientes aparecem associados ao papel de caixa: a remuneração é relativamente baixa para a função (2,5 salários mínimos, em outubro de 1999) em face do custo de vida alto do Distrito Federal, constituindo fonte de queixas unânimes dos sujeitos, e a prática gerencial, não prevista nas normas, de concessão aos frentistas de adiantamentos de parte do salário.

Logo, constata-se um cenário sociotécnico em que os frentistas se tornam vulneráveis à lógica de funcionamento da organização, cuja concepção do trabalho e do papel dos sujeitos é de caráter tecnoprodutivista, fornecendo elementos para compreender a rotatividade sistemática. Os efeitos perversos deste cenário são descritos exemplarmente por um frentista, evidenciando um paradigma organizacional: "a gente é pressionado de um lado e de outro. Se você pede a documentação, o cliente acha que é abuso. Se você não pede, é pressionado pela empresa. 
Se o cliente reclama para o gerente, a gente deixa de ter razão, porque para a empresa o cliente tem sempre razão e, se o cheque volta, sou eu que pago".

Os elementos dessa moldura, explorados a partir da discrepância entre o trabalho prescrito e o trabalho real, contribuem para contextualizar as representações negativas do emprego e do trabalho recorrentes nos depoimentos dos frentistas, marcados pelo desejo de sair da empresa e procurar outro emprego: "eu não pretendo ficar aqui por muito tempo"; "emprego tá difícil, mas para ganhar tão pouco é melhor sair mesmo"; "as coisas até que são fáceis, quando se tem prática, mas não dá para ficar"; "é muito burocrático esse serviço"; "não compensa trabalhar aqui. Foi por falta de opção. O salário é muito pouco e ainda tem os descontos"; "fico porque sou casado e tenho família para criar, mas o pessoal solteiro sai logo. É muita responsabilidade receber dinheiro e cansa ficar em pé".

\section{Conclusão}

O trajeto percorrido pela Análise Ergonômica do Trabalho forneceu elementos empíricos para um novo olhar na ocorrência da rotatividade no contexto observado. As contribuições, limites e perspectivas são abordados a seguir.

\section{A Empresa Treina, mas na Prática é Outra Coisa: do Superfrentista Prescrito ao Frentista Real}

Do ponto de vista do trabalho prescrito, os resultados do estudo evidenciam os traços estruturantes da concepção organizacional da função frentista em termos do perfil previsto do funcionário e, sobretudo, das tarefas que lhe são atribuídas. O exame desses resultados dá visibilidade ao modelo idealizado de funcionário e de trabalho (Leplat, 1991), expressando o modo de ser habitual ou a lógica da instituição no contexto do serviço de atendimento (Ferreira, 1998). Os elementos constituintes dessa lógica, veiculados pela prescrição do trabalho, mostram a primeira face da moeda na construção de um quadro explicativo da rotatividade.

A concepção do trabalho prescrito tem como característica central a sua orientação tecnocêntrica e a sua filiação ao pensamento taylorista (Montmollin, 1981). Os indícios dessa característica são diversos, e três deles servem aqui de ilustração.

- O paradigma the right man in the right place permeia as normas de conduta profissional do atendente: homem disciplinado, assíduo, pontual, com boa apresentação e dedicação ao trabalho é o funcionário certo (ética e moralmente) 
para o desempenho da função de frentista. Assim, a função certa necessita de um frentista certo que reúna as qualidades desejadas na ótica administrativa que inspira a elaboração das normas, cuja vocação é de código de conduta.

- A perspectiva organizacional é limpidamente manifesta: "adaptar o atendente para a observância e o acatamento das normas". Na contramão do pressuposto central em ergonomia de adaptar o trabalho ao homem, a concepção do prescrito não considera a variabilidade intra e interindividual dos sujeitos (Abrahão, 1993). Assim, o comportamento adaptado do funcionário não é apenas um desejo da organização, mas uma obrigação imposta aos sujeitos. As ferramentas de controle do desempenho (ficha de acompanhamento, relatório de adaptação) no período de experiência e a ameaça permanente de punições, são ingredientes imprescindíveis para operacionalizar a adaptação esperada.

- A concepção do perfil da função idealiza um frentista de múltiplos papéis, tendo como centro de gravidade a função caixa. Nesse caso, o indício de descompasso com a atividade é flagrante, pois o caráter multifuncional do frentista veicula implicitamente múltiplas atribuições, responsabilidades e competências, configurando o perfil do funcionário como um superfrentista: eficiente, eficaz e afetuoso. Nesse último caso, a prescrição do elogio ao colega de trabalho é uma pérola da pensée gerencial em recursos humanos e do caráter esquizo das normas, pois busca formalizar uma atitude importante, retirando-a do cenário da informalidade, onde a sua probabilidade de eficácia aumenta consideravelmente.

Uma reflexão sobre os resultados obtidos parece indicar que a concepção de homem subjacente à racionalidade taylorista, permanece viva na instituição que serviu de campo do estudo. Nesta concepção, a busca da produtividade e da rentabilidade é a prioridade; o homem é fator de ajuste, e no centro das preocupações da organização encontra-se o imperativo da técnica e do desempenho em detrimento das necessidades, projetos e expectativas dos sujeitos. Daí por que ela pode ser denominada concepção tecnocêntrica. Autonomia, organização flexível do trabalho, enriquecimento de tarefas, ou mudanças introduzidas pelas novas tendências gerenciais na reestruturação produtiva e que reconfiguram a identidade das organizações, parecem distantes da realidade estudada (Terssac, 1995).

Do ponto de vista do trabalho real, os resultados do estudo evidenciam as características centrais da atividade dos sujeitos em termos do fluxo habitual do processo de trabalho e, principalmente, das múltiplas exigências físicas, cognitivas e psíquicas, que expressam o custo humano do trabalho (Wisner, 1987). De modo geral, tais resultados servem de indicadores da discrepância entre o trabalho prescrito e o trabalho real, e expressam elementos do modo operatório usual ou lógica do atendente no contexto do serviço de atendimento (Ferreira, 1998). 
O exame dos dados referentes ao trabalho real, oriundos da análise da atividade, mostra a outra face da moeda da rotatividade de pessoal na instituição em foco, complementando o quadro explicativo esboçado neste estudo.

Os traços gerais das atividades dos frentistas chamam a atenção para as peculiaridades do serviço de atendimento ao público, em particular os custos específicos do desempenho da função. Diferentemente do perfil prescrito da função, a análise da atividade mostra que, nas situações de atendimento, ela assume um perfil real singular, destacando-se os elementos a seguir.

- O traço característico do trabalho real dos frentistas é a predominância da função de caixa. Ela é estruturadora da atividade e, em conseqüência, portadora dos riscos e exigências de resultados mais importantes que marcam a função de frentista.

- O trabalho mental predominante na carga de trabalho, sobretudo por conta da função de caixa, que veicula implicitamente uma quantidade e variabilidade considerável de informações para serem captadas, armazenadas, evocadas e tratadas para o planejamento e operacionalização das ações. Esse trabalho mental se agrava em função da dinâmica das situações, dos limites das condições de trabalho existentes e da ocorrência de incidentes críticos, agregando indicadores de complexidade à atividade dos frentistas (Ferreira, 1996).

- O esgotamento das estratégias de regulação dos frentistas em função da combinação de diferentes fatores relativos à situação, às práticas organizacionais e ao custo, sobretudo monetário, do furo de caixa. Essa falência das estratégias operatórias e dos esforços permanentes para gerir as exigências diversas, no embalo do pagamento com o próprio salário dos cheques devolvidos, torna insuportável a permanência dos frentistas na função, alimentando, dessa forma, a gênese da rotatividade.

O desempenho eficiente e eficaz da função exige dos frentistas a construção de representações singulares para agir nas situações com base na sua formação, experiência e necessidades impostas pela situação. Com base na elaboração dessas representações, os atendentes organizam, estruturam e planejam as suas condutas em interações com o contexto de atendimento, com base em processo incessante de assimilação e acomodação (Weill-Fassina, Dubois e Rabardel, 1993); mas essa inteligência criadora, posta à prova a cada momento, não é suficiente para mantê-los na função. A lógica de funcionamento da instituição, em particular a concepção que dá origem à organização do trabalho, engendra a demissão sistemática. 


\section{Elementos Explicativos da Rotatividade: A Atividade do Frentista entre o Caixa de Bomba e a Bomba do Caixa}

Os dados resultantes da AET fornecem uma fotografia preliminar da gênese da rotatividade sistemática de pessoal na empresa em estudo. A presente pesquisa contribui para enriquecer o parco conhecimento na área de ergonomia do serviço de atendimento ao público e aprimorar o modelo teórico-metodológico adotado. Os resultados permitiram elaborar um quadro ilustrativo das condições de trabalho da função frentista no serviço de atendimento ao público em uma unidade da rede de distribuição de combustível. Em síntese, a análise ergonômica autoriza a seguinte afirmação: o trabalho de frentista consiste, fundamentalmente, em uma atividade de caixa escriturário, veiculando uma carga de trabalho mental significativa, cuja falência em situações críticas impõe prejuízos, sobretudo monetários, condições que, combinadas com baixo salário e a prática dos adiantamentos, impelem o frentista a não permanecer por muito tempo na função.

Os resultados apresentados pelo estudo ajudam a compreender uma dimensão da origem da rotatividade sistemática; mas, dado seu caráter multicausal (Chiavenato, 1995; Epstein, 1999; Brannik, 1999), restringe sobremaneira a possibilidade de interpretações mais conclusivas sobre as condições de surgimento da rotatividade; por exemplo, que influência os fatores extra-organizacionais (família, mercado etc.) podem estar jogando na gênese da rotatividade de pessoal? Três aspectos caracterizam os limites do estudo: (1) o alcance de seus resultados restringe-se a fornecer parâmetros gerais para realização de novos estudos; (2) a necessidade do levantamento de dados mais aprofundados sobre a lógica do usuário, que possibilitasse enriquecer o estudo da temática; e (3) a carência de dados quantitativos para complementar a avaliação dos componentes da carga de trabalho; por exemplo, custo postural dos frentistas ao longo da jornada.

$\mathrm{O}$ argumento da inadaptabilidade dos funcionários como causa da rotatividade, explicação centrada na dimensão da responsabilidade individual, sofre uma inversão e chama-se a atenção para a responsabilidade da organização na origem do problema da rotatividade epidêmica. Neste sentido, o enfrentamento da rotatividade impõe: (1) reconceber o trabalho e a lógica de atendimento, fundamentando-os nas necessidades, objetivos e expectativas dos funcionários e usuários; e (2) promover melhoria nas condições e relações de trabalho existentes. O superfrentista prescrito nas normas distancia-se do frentista real das situações de atendimento. Nesse contexto, torna-se compreensível o caráter tecnocêntrico da organização no duplo sentido da fala do frentista: "a empresa não perde nada, só a gente". 


\section{NOtAS}

${ }^{1}$ Interessante registrar que o texto das normas é acompanhado de notas de rodapé em cada página, onde desfilam frases ilustrativas, inspiradas no esprit du capitalisme, assinalado por Weber (1964): "O sucesso da empresa é o sucesso das pessoas, não se constrói uma empresa vencedora sem pessoas vencedoras". "A empresa só poderá melhorar a sua vida, se você melhorar a dela". "Não se acostume com o desperdício. O prejuízo é nosso". "Pense sempre no melhor, trabalhe sempre para o melhor e espere sempre o melhor". "A excelência é fazer algo comum de maneira incomum". "Sorria para as pessoas. Lembre-se de que acionamos 72 músculos para franzir a testa e somente 14 para sorrir".

${ }^{2}$ O custo biomecânico intenso do trabalho de pé, que caracteriza a atividade dos frentistas, explicase parcialmente pelo fato de a empresa não cumprir o que determina a legislação atual em medicina e segurança do trabalho (MTb, 1978), em particular a NR-17, que estabelece: "Para as atividades profissionais em que os trabalhos devam ser realizados em pé, deverão ser colocados assentos em locais em que possam ser utilizados durante as pausas que os serviços permitirem". Tais assentos devem atender aos requisitos mínimos de conforto (por exemplo, altura ajustável) e serem disponibilizados conforme a quantidade de funcionários. No caso da empresa em exame, deveriam existir, pelo menos, dois assentos.

\section{Referências Bibliográficas}

ABRAHÃO, J.

Ergonomia : modelo, métodos e técnicas. In: II CONGRESSO LATINO-AMERICANO/ VI SEMINÁRIO BRASILEIRO DE ERGONOMIA (1993 : Brasília). Anais... Brasília : UnB/ IP, 1993.

BRANNICK, J.

Decreasing the staggering costs of turnover in your organization. [online] Disponível na Internet via WWW.URL : http://www.brannick.com. 1999.

BRITO, J. C.

Procurando compreender os con- ceitos de carga, trabalho e risco (tecnológico). Revista Brasileira de Saúde Ocupacional, v. 19, n. 72, p. 38-39, 1991.

CHIAVENATO, I.

Recursos humanos. 5. ed. São Paulo : Atlas, 1995.

DANIELLOU, F.;

LAVILLE A.;

TEIGER C.

Ficção e realidade do trabalho operário. Revista Brasileira de Saúde Ocupacional, v. 68, n. 17, p. 7-13, 1989. 
EPSTEIN, J. J.

Reducing turnover through training. High Volume Printing, v. 17, p. 20-24, Oct. 1999.

FALZON, P.;

LAPEYRIÈRE, S.

L'usager et l'opérateur : ergonomie et relations de service.

Le Travail Humain, v. 61, n. 1, p. 69-90, 1998.

FERREIRA, L. L.;

MARCELLIN, J.

Orientações atuais da metodologia ergonômica na França. Revista Brasileira de Saúde Ocupacional, v. 11, n. 41, p. 65, 1983.

FERREIRA, M. C.

Utilité e utilisabilité de l'infomatique dans la gestion du travail bancaire. Paris, 1998. Thèse (Doctorat en Ergonomie) - EPHE.

A fila não anda... Gazeta Mercantil, Brasília, n. 202, ano I, p. 2, 4 ago. 1999. Caderno GM Distrito Federal.

Serviço de atendimento ao público : o que é? como analisá-lo? Esboço de uma abordagem teórico-metodológica em ergonomia. Revista Multitemas. 200_. no prelo.
FERREIRA, M. C.;

CARVALHO, R.;

SARMET, M.

Ergonomia do serviço de atendimento ao público : um estudo de caso. In: IX CONGRESSO BRASILEIRO DE ERGONOMIA (Salvador : 1999). Anais... Salvador : [s.n.], 1999.

GONÇALVES, R. M.;

FERREIRA, M. C.

Serviço de atendimento ao público e home-pages governamentais. In: IX CONGRESSO BRASILEIRO DE ERGONOMIA (Salvador : 1999). Anais... Salvador : [s.n.], 1999.

GUÉRIN, F. et al.

Compreendre le travail pour le transformer : la pratique en Ergonomie. Paris : ANACT, 1997.

HARKINS, P. J.

Why employees stay or go workforce. Workforce, v. 77, n. 10, p. 74-78, Oct. 1998.

LAURELL, A. C.; NORIEGA, $M$.

Processo de produção e saúde : trabalho e desgaste operário. São Paulo : Hucitec, 1989. 
LAVILLE, A.

L'ergonomie. 5. ed. Paris : P.U.F., 1993.

LEPLAT, J.

Compétence et ergonomie. In: AMALBERTI, R.; MONTMOLLIN, M. DE; THEUREAU, J. Modèles en analyse du travail. Margada : Liège, 1991.

LEPLAT, J.;

HOC, J. M.

Tache et activité dans l'analyse phychologique des situations. Cahiers de Psychologie Cognitive, v. 3, n. 1, p. 49-63, 1983.

MONTMOLLIN, M.

Le taylorisme à visage humain. Paris : P.U.F., 1981.

L'ergonomie. Paris : La Découverte, 1990.

MORAES, A.;

MONT'ALVÃO.

Ergonomia, conceitos e aplicações. Rio de Janeiro : Editora 2AB, 1998.

TAYLOR, F. W.

Princípios da administração científica. 7. ed. São Paulo : Atlas, 1987.
TERSSAC, G.

Autonomie dans le travail. Paris : Presse Universitaire Française, 1992.

Le travail organisé : faut-il repenser le travil? In: XXX CONGRÉS DE LA SOCIÉTÉ D'ERGONIMIE DE LANGUE FRANÇAISE (Paris : 1995). Actes.... Paris : [s.n.], 1995.

WEBER, M.

L'éthique protestante et l'esprit du capitalisme. Paris : Traduction Plon, 1964.

WEILL-FASSINA, A.

L'analyse des aspects cognitifs du travail. In : DADOY, M. et al. (Orgs.). Les analyses du travail enjeux et formes. Paris : Cereq, 1990.

WEILL-FASSINA, A.;

DUBOIS, D.;

RABARDEL, P.

Représentations pour l'action. Paris : Octares Editions, 1993.

WISNER, A.

Por dentro do trabalho - ergonomia : métodos e técnicas. São Paulo : Oboré, 1987. 